\title{
Severe reversible cardiac failure associated with methanol intoxication
}

\author{
Augusto Cavalli, Alberto Volpi, Aldo Pietro Maggioni, Maurizio Tusa and \\ Gabriella De Pieri
}

Department of Cardiology, 'G. Fornaroli' Hospital, 20013 Magenta, Milano, Italy

\begin{abstract}
Summary: Methanol intoxication produces a well recognized clinical picture characterized by gastrointestinal, ocular and nervous system symptoms. The effect of poisoning on the cardiovascular system has not been well documented.

We report the case of a 55 year old man whose acute methanol intoxication caused severe reversible cardiac failure. This represents the first description of an association between methanol toxicity and acute cardiac dysfunction in man.
\end{abstract}

\section{Introduction}

Though metabolic, gastrointestinal, nervous and ocular toxic effects are common in oral methanol poisoning, ${ }^{1}$ cardiac involvement has not so far been reported as a prominent manifestation of the disease. We describe here a case of severe reversible cardiac failure secondary to methanol intoxication.

\section{Case report}

A 55 year old man was admitted to the Intensive Care Unit because of dyspnoea, cyanosis and mental confusion. Twenty four hours before admission he had complained of vague malaise, vomiting, frontal headache and blurred vision. His history was unremarkable except for chronic alcohol abuse.

On admission the patient was comatose with tachycardia, tachypnoea, arterial hypotension $(80 \mathrm{~mm} \mathrm{Hg})$ and scanty bilateral pulmonary rales. Shortly after admission respiratory arrest supervened, requiring intermittent positive pressure ventilation. Arterial gas analysis disclosed severe metabolic acidosis (pH 6.77. and base excess $-34 \mathrm{mmol} / \mathrm{l}$ ) and hypocarbia $\left(\mathrm{PCO}_{2} 26 \mathrm{~mm} \mathrm{Hg}\right)$. The electrocardiogram (ECG) showed sinus tachycardia, right bundle branch block and normal $T$ wave morphology. Cardiomegaly with pulmonary venous congestion and oedema were evident on the chest X-ray. Right atrial pressure was $19 \mathrm{~cm}$ of saline. Repeated serum creatine kinase (CK-

Correspondence: A. Cavalli M.D.

Accepted: 15 April 1987
MB) determinations were within the normal range.

The metabolic acidosis was promptly treated with buffers; arterial gas analysis improved within a few hours (pH 7.20-7.30; $\mathrm{PCO}_{2} 20-25 \mathrm{~mm} \mathrm{Hg}$ ). Further stabilization was achieved in the next few days (pH 7.44 and $\mathrm{PCO}_{2}$ around $30 \mathrm{~mm} \mathrm{Hg}$ ). However coma persisted and cardiac failure did not improve despite dopamine, diuretics and digoxin.

On the third day in hospital, stable bifascicular block developed (right bundle branch block plus left anterior hemiblock) and a paroxysm of self-limiting atrial fibrillation was recorded. M-mode echocardiogram indicated increases of left ventricular enddiastolic and end-systolic dimensions (respectively $65 \mathrm{~mm}$ and $56 \mathrm{~mm}$ ), with reduction of the fractional shortening $(14 \%)$. The anterior-basal interventricular septum appeared akinetic and mitral valve echocardiogram was consistent with elevated left ventricular end-diastolic pressure. Two-dimensional tomograms revealed a dilated, poorly contractile left ventricle.

On the same day high formate values were found in plasma $(206 \mathrm{mg} / \mathrm{dl})$, whole blood $(158 \mathrm{mg} / \mathrm{dl})$ and urine $(5.6 \mathrm{~g} / \mathrm{l})$ and the diagnosis of methanol poisoning was made. ${ }^{2}$

The patient was given ethanol and haemodialysis was performed following which formate was rapidly cleared from plasma and urine. Coma progressively improved, the patient was extubated and awoke 8 days after admission, with permanent visual impairment. Arterial and atrial pressures returned to normal values and the chest $\mathrm{X}$-ray was normal within 28 days. The ECG pattern of left anterior hemiblock disappeared, 
but diffuse $\mathrm{T}$ wave abnormalities developed. A further echocardiogram indicated the restoration of normal ventricular dimension with good contractility. Mitral valve echo was normal.

A toxic concentration of methanol was found in the wine usually drunk by the patient, but it was impossible to estimate the exact amount ingested.

\section{Discussion}

There are only a few reports describing the toxic effects of methanol and its metabolites on the cardiovascular system. According to in vitro studies with rat tissue homogenates, cardiac tissues metabolize methanol. ${ }^{3}$ Moreover cardiac dilatation and myocyte degeneration have been described in intoxicated animals ${ }^{4}$ and intravenous methanol reduced cardiac output, stroke volume and systemic arterial pressure, and increased total peripheral resistances in dogs. ${ }^{5}$ Therefore it is reasonable to assume that in acutely intoxicated humans, methanol and its metabolites exert a specific depressant action upon the myocardium. This assumption is consistent with post-mortem observations showing engorgement of the pulmonary vessels, pulmonary oedema and widespread passive organ congestion both in animals and humans. ${ }^{4}$

Although minor electrocardiographic changes have been reported, ${ }^{6}$ to the best of our knowledge no single study has focused on acute cardiac failure secondary to methanol intoxication in man.

In our patient heart failure was suspected on the basis of both clinical and laboratory data. Echocardiographic examination provided substantial evidence

\section{References}

1. Ritchie, J.M. The aliphatic alcohols. Chapter 18: Methyl alcohol. In: Goodman Gilman, A, Goodman, L.S., Rall, T.W. \& Murad, F. (eds) Goodman and Gilman's: The Pharmacological Basis of Therapeutics, 7th ed. Macmillan, New York, 1985, pp 381-382.

2. Alha, A.R., Raekallio, J. \& Mukula, A.L. Detection of methanol poisoning. Ann Med Exp Fenn 1958, 36: 444451.

3. Koivusalo, M. Studies on the metabolism of methanol and formaldehyde in the animal organism. Acta Physiol Scand 1956, 39: (suppl 131) 1-103.

4. Rowe, V.K. \& McCollister, S.B. Alcohols. In: Clayton, G.D. \& Clayton, F.E. (eds) Patty's Industrial Hygiene and of cardiac dysfunction, showing an enlarged, diffusely hypokinetic left ventricle during the acute phase of $\frac{\varrho}{c}$ poisoning.

The development of ECG abnormalities might be viewed as further evidence of diffuse myocardial $\overline{0}$ damage. On the other hand an ischaemic origin of the severe pump failure appears unlikely, given the absence of any serum CK-MB rise and of typical ECG changes.

Severe metabolic acidosis might have contributed to myocardial dysfunction. ${ }^{7}$ In fact it has been suggested that acidosis plays a role in the development of some of the effects of methanol poisoning. However the cardiotoxic effect described in our patient cannot be accounted for merely by acidosis. No such prolonged effects are seen in other types of severe acidosis. ${ }^{6}$ Moreover, though the acidosis was promptly corrected, the cardiac (and nervous) effects of intoxication lasted several days, consistently with the presence of formate in blood and urine.

There is no direct correlation between acidosis and 은 specific toxic effects of methanol, as in animal experiments slight or no acidosis has been described, and only primates develop acidosis after methanol. ${ }^{6}$

This therefore appears to be the first description of an association between methanol toxicity and acuto cardiac dysfunction in man, and suggests that acuto cardiac failure may play an important role in methan poisoning.

\section{Acknowledgement}

We are indebted to Mrs Judy Baggott for style editing the manuscript.

Toxicology, vol 2C. Toxicology. John Wiley \& Sons, New York, 1982, pp 4527-4708.

5. DeFelice, A., Wilson, W. \& Ambre, J. Acute cardiovascular effects of intravenous methanol in anesthetized dog. Toxicol Appl Pharmacol 1976, 38: 631-638.

6. Koivusalo, M. Methanol. In: Tremolieres, J. (section ed) Int Encycl Pharmacol Ther. Sec. 20 vol II. Alcohols and 오 Derivatives. Pergamon Press, New York, 1970, pp 465505.

7. Cousin, M.T. Troubles de l'equilibre acido-basique chez l'adulte. Encycl Med Chir Paris, Anesthesie-Reanimation 1983, 36860: A50, 12-14. 